\title{
The roles of ENSO on the occurrence of abruptly recurving tropical cyclones over the Western North Pacific Ocean Basin
}

\author{
N. K. W. Cheung \\ School of Earth Sciences and Geography, Kingston Univ., Penrhyn Road, Kingston upon Thames, London, KT1 2EE, UK
}

Received: 9 May 2005 - Revised: 22 December 2005 - Accepted: 26 December 2005 - Published: 30 January 2006

\begin{abstract}
The abruptly recurving tropical cyclones over the Western North Pacific Ocean Basin during El Niño and La Niña events are studied. Temporal and spatial variations of these anomalous tracks under different phases of ENSO are shown. The anomalies of the pressure field in relation to ENSO circulation for the occurrence of the abruptly recurving cyclone tracks are investigated using fuzzy method. These are supplemented by wind field analyses. It is found that the occurrence of recurving-left (RL) and recurvingright (RR) tropical cyclones under the modification of the steering currents, including the re-adjustment of the westerly trough, the expansion or contraction of the sub-tropical high pressure, the intensifying easterly flow and the strengthening of the cross-equatorial flow, can be in El Niño or La Niña events. Evidently, there is a higher chance of occurrence of anomalous tropical cyclone trajectories in El Niño rather than La Niña events, but there is not any pronounced spatial pattern of anomalous tropical cyclone tracks. By analyzing the pressure-field, it is seen RL (RR) tropical cyclones tend to occur when the subtropical high pressure is weak (strong) in El Niño and La Niña events. More importantly, how the internal force of tropical cyclones changed by the steering current, which relies upon the relative location of tropical cyclones to the re-adjustment of the weather systems, shows when and where RL and RR tropical cyclones occur in El Niño and La Niña events.
\end{abstract}

\section{Introduction}

Over the Western North Pacific Ocean Basin $\left(0^{\circ}-60^{\circ} \mathrm{N}\right.$, $100^{\circ}-180^{\circ} \mathrm{E}$ ), once tropical cyclones have formed, under the influence of the steering current, most of them move westward, northward or northwestward, and some dissipate or recur over the ocean to follow a northeastward or southwestward direction while some make landfall at coastal areas.

Correspondence to: N. K. W. Cheung

(k.w.cheung@kingston.ac.uk)
However, some tropical cyclone tracks are defined as anomalous or abnormal. According to the definition of South China Typhoon Research Committee (1977, 1978) (Fig. 1), a tropical cyclone which recurves left within $24 \mathrm{~h}$, with a recurving angle (comparing its mean path of $12 \mathrm{~h}$ before and after the occurrence of its recurvature) $\geq 30^{\circ}$ is a recurving-left (RL) tropical cyclone. A tropical cyclone which recurves right within $24 \mathrm{~h}$, with a recurving angle (comparing its mean path of $12 \mathrm{~h}$ before and after the occurrence of its recurvature) $\geq 45^{\circ}$; or a tropical cyclone moving northwestward which suddenly turns to east or northeast but there must be a distance $\leq 2.5^{\circ}$ latitude between two points of the track at $1^{\circ}$ longitude east of its recurving point is a recurving-right (RR) tropical cyclone. A tropical cyclone meanders or oscillates about a mean path, with at least two recurving points, each must be $\geq 30^{\circ}$, there must be $\geq 12 \mathrm{~h}$ between two recurving points and $>1 / 2^{\circ}$ latitude between at least two recurving points and the mean path is a meandering (M) tropical cyclone. A tropical cyclone's track which has or nearly has an intersection (there must be $\leq 1 / 2^{\circ}$ latitude and $\geq 24 \mathrm{~h}$ between two points of the track) is a looping (L) tropical cyclone.

\section{Temporal and spatial variation of anomalous tropical cyclone tracks}

There is a large interannual variability of anomalous tropical cyclone tracks (Cheung, 2004). There is a higher chance of occurrence of anomalous trajectories, particularly looping and recurving-right, of tropical cyclones in El Niño rather than La Niña events over the Western North Pacific (Fig. 2.1). However, there is not a pronounced pattern of where these anomalous tropical cyclone tracks occurred (Fig. 2.2). Since the abruptly recurving cyclone tracks often invalidate the forecast and cause substantial damages along their paths, this paper attempts to study the roles of ENSO on causing the recurving-left and recurving-right tropical cyclones over the Western North Pacific Basin. 


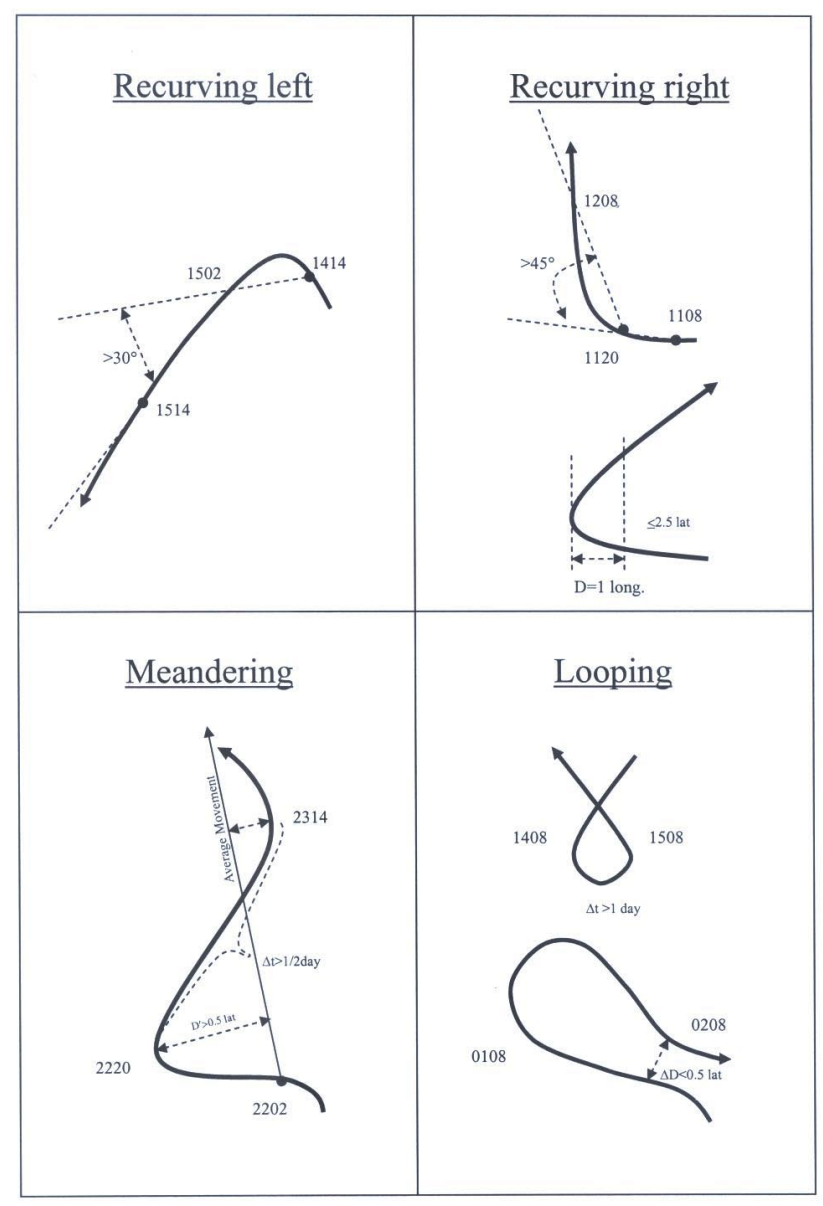

Fig. 1. Different types of anomalous tropical cyclone tracks (After South China Typhoon Research Committee, 1977, 1978). Four digit numbers are time.

\section{Occurrence of recurving-left and recurving-right tropical cyclone tracks during El Niño and La Niña events}

The resultant direction of a tropical cyclone is due to a combination of three basic forces: the basic pressure field (i.e. pressure gradient force), Coriolis force (or geostrophic deflection force) and the internal force of the tropical cyclone caused by the rotation of the earth (Yu and Lu, 1986). However, the re-modification or sudden change of the largescale environmental flows or of the weather systems due to anomalous ENSO related circulation would change the pressure- and the wind-fields. Therefore the examination of the changes of the pressure- and wind-fields in which the tropical cyclones embedded can give an understanding of the circulation anomalies behind the occurrence of recurving-left and recurving-right tropical cyclones.

\subsection{Pressure field analyses}

As the flow in the mid-troposphere has the best correlation with cyclone movement (Chan and Gray, 1982), thus $500 \mathrm{hPa}$ geopotential height is chosen to represent the sub- tropical high pressure. Two indices of the sub-tropical high pressure (STHPI) of Central Meteorological Observatory (CMO), China, are adopted (Appendix A). The change of the STHPI $24 \mathrm{~h}$ before and on the day the anomalous tropical cyclones occur shows the role of it upon the occurrence of these cyclone tracks. To do this, the cumulative frequencies of the difference of STHPI, area and intensity, $24 \mathrm{~h}$ before and on the day the directional change of all tropical cyclones (including the normal recurving and abruptly recurving tracks) occurred during 1958-1998 for the Western North Pacific Basin are assigned the membership functions in the fuzzy method. The most representative cases can be obtained by three-level method:

$f: X \rightarrow P_{3}=\left\{A_{1}, A_{2}, A_{3}\right\}$

Correspondingly, two boundaries, $\xi_{1}$ and $\xi_{2}$, are set for delimiting level $A_{1}$ and $A_{2}$, and $A_{2}$ and $A_{3}$ :

$$
\begin{array}{rll}
A_{1} & \text { when } & x \leq \xi_{1} \\
A=A_{2} & \text { when } & \xi_{1}<x \leq \xi_{2} \\
A_{3} & \text { when } & \xi_{2}<x
\end{array}
$$

so the membership functions of these fuzzy statistical experiments would be

$\mu_{A_{1}}(x)=\int_{x}^{+\infty} p_{\xi_{1}}(y) d y$
$\mu_{A_{3}}(x)=\int_{-\infty}^{x} p_{\xi_{2}}(y) d y$
$\mu_{A_{2}}(x)=1-\mu_{A_{1}}(x)-\mu_{A_{3}}(x)$

under normal distribution of $\xi_{1}$ and $\xi_{2}$ they can be transformed to

$$
\begin{aligned}
& \mu_{A_{1}}(x)=1-\Phi\left(\frac{x-m_{1}}{\sigma_{1}}\right) \\
& \mu_{A_{3}}(x)=\Phi\left(\frac{x-m_{2}}{\sigma_{2}}\right) \\
& \mu_{A_{2}}(x)=\Phi\left(\frac{x-m_{1}}{\sigma_{1}}\right)-\Phi\left(\frac{x-m_{2}}{\sigma_{2}}\right)
\end{aligned}
$$

where $m_{1}$ and $\sigma_{1}$ is the mean and standard deviation of $\xi_{1}$, $m_{2}$ and $\sigma_{2}$ is the mean and standard deviation of $\xi_{2}$ and $\Phi(x)$ is the cumulative density function. By compositing the cases of anomalous tracks with high membership functions $\mu_{A_{1}}(x)$, the anomalies of the subtropical high pressure for the occurrence of anomalous tropical cyclones are shown.

\section{El Niño and La Niña}

During 1958-1998, there were 401 normal recurving tropical cyclones and 272 anomalous tracks over the Western North Pacific Ocean Basin. For all El Niño (La Niña) events there were 13 (11) RL and 20 (13) RR tropical cyclone tracks. Figure 3.1 shows the subtropical high pressure (STHP) anomaly patterns RL and RR tropical cyclones are 


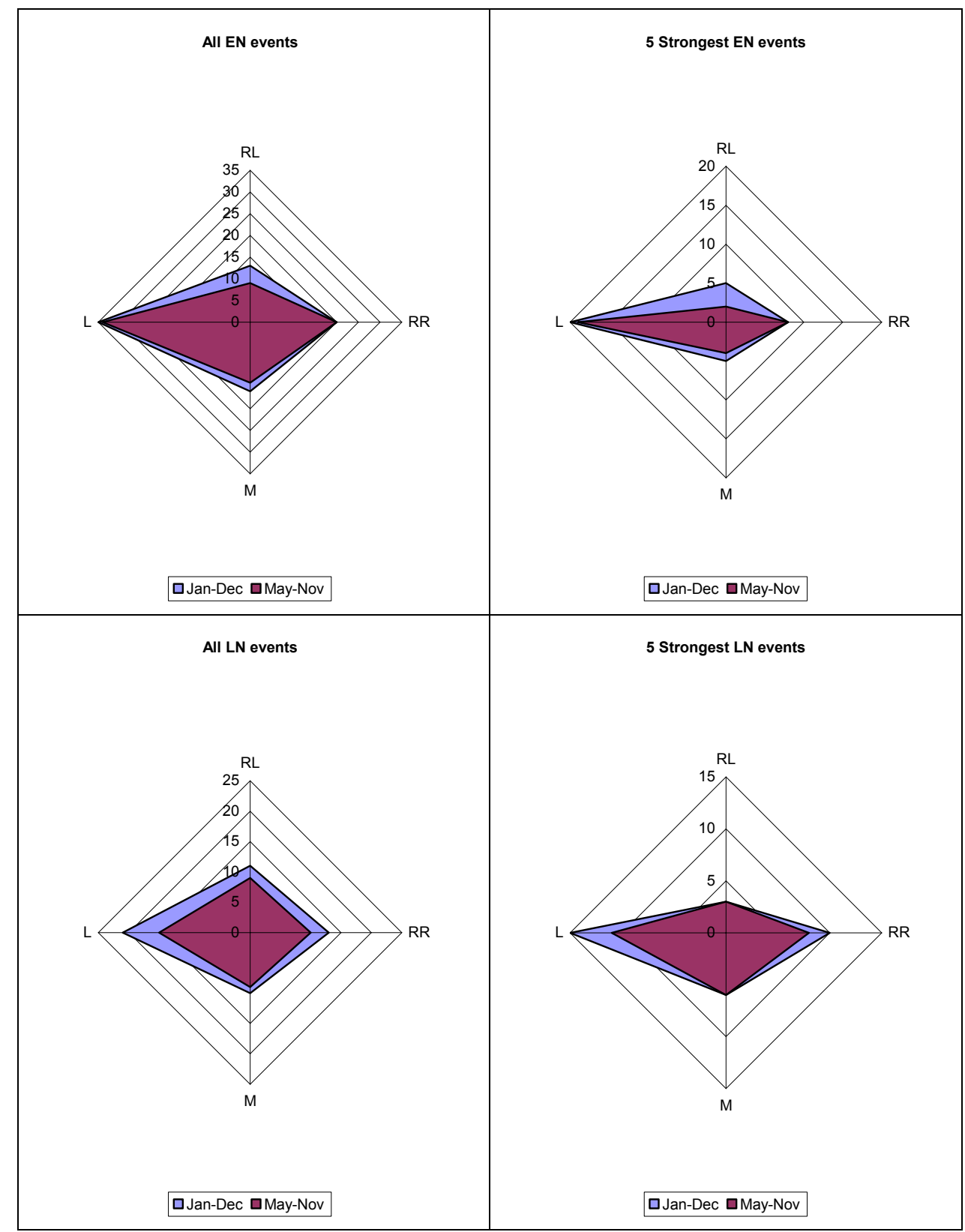

Fig. 2.1. The distribution of different anomalous tropical cyclone tracks ( $R L$ - recurving left, $R R$ - recurving right, $M-$ meandering, $L$ - looping) over the Western North Pacific Ocean in 1958-98. Their distribution patterns of the whole year and of the typhoon season are shown in blue and red colour respectively for all El Niño events and 5 strongest El Niño events (upper panels), and all La Niña events and 5 strongest La Niña events (lower panels).

more likely to occur over the Western North Pacific. It is seen that the occurrence of RL (RR) tropical cyclones are related to weak (strong) STHP activity. The presence of a negative anomaly may imply the retreat of the STHP eastward or northward and/or the intensity weakened. Without the guidance of the STHP, tropical cyclones are easily recurved to the left if influenced by other weather systems, e.g. the strong cross-equatorial flow, or another tropical cyclone nearby through strengthening the southern part of the tropical cyclone (Yu and Lu, 1986). On the other hand, the sudden strengthening of the STHP activity may be due to the adjustment of the Rossby waves in the westerly belt (Ding, 1994). The positive STHP anomaly can block the usual tropical cyclone movement. Through enhancing the development of the northern part of the tropical cyclones, tropical cyclones are more likely to recurve right. Figures 3.2 and 3.3 respectively portray the patterns of STHP anomalies when RL and RR tropical cyclones occur in El Niño and La Niña events. It is seen that in El Niño the RL (RR) tropical cyclones tend to occur when the STHP is weak (strong). They are more obvious in La Niña. 


\section{The occurrence of anomalous WNP Trapical Cyclone Tracks in 5 strongest El Nino events during 1958-98}

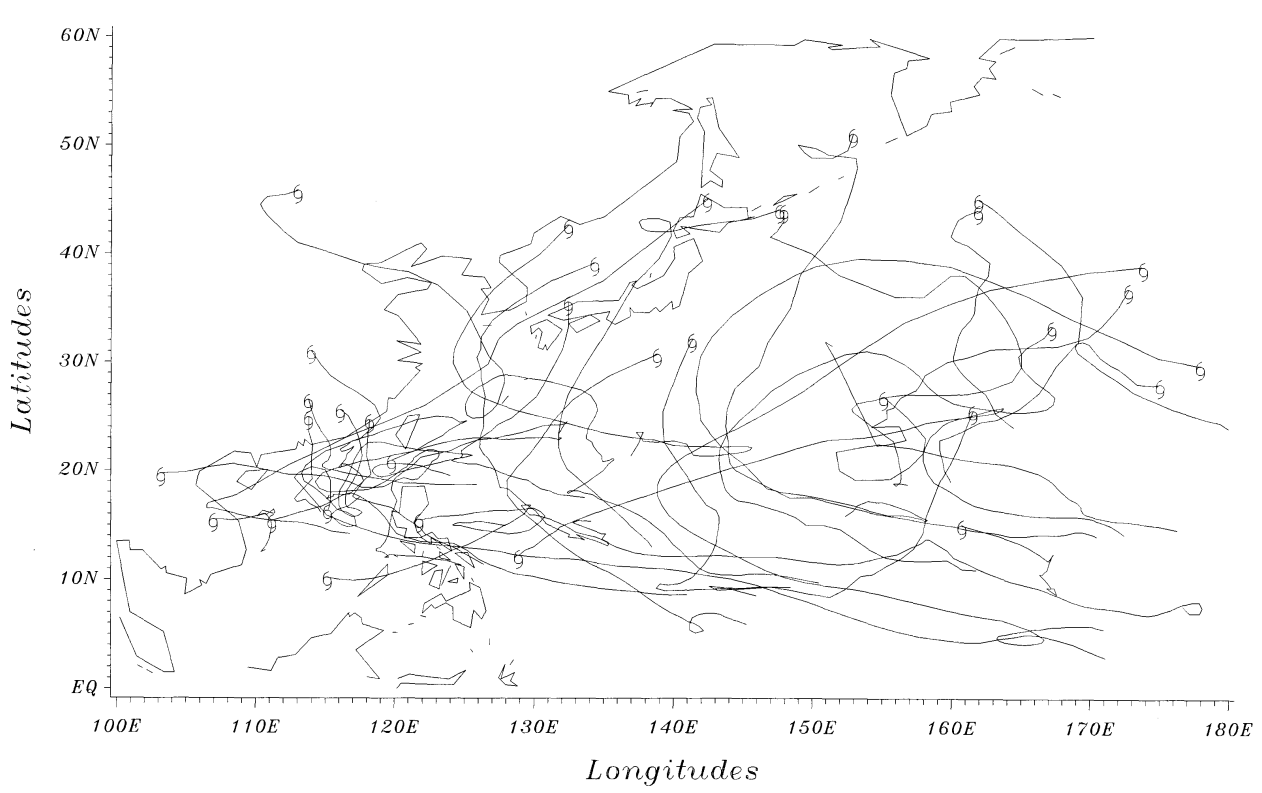

The occurrence of anomalous WNP Tropical Cyclone Tracks in 5 strongest La Nina events during 1958-98

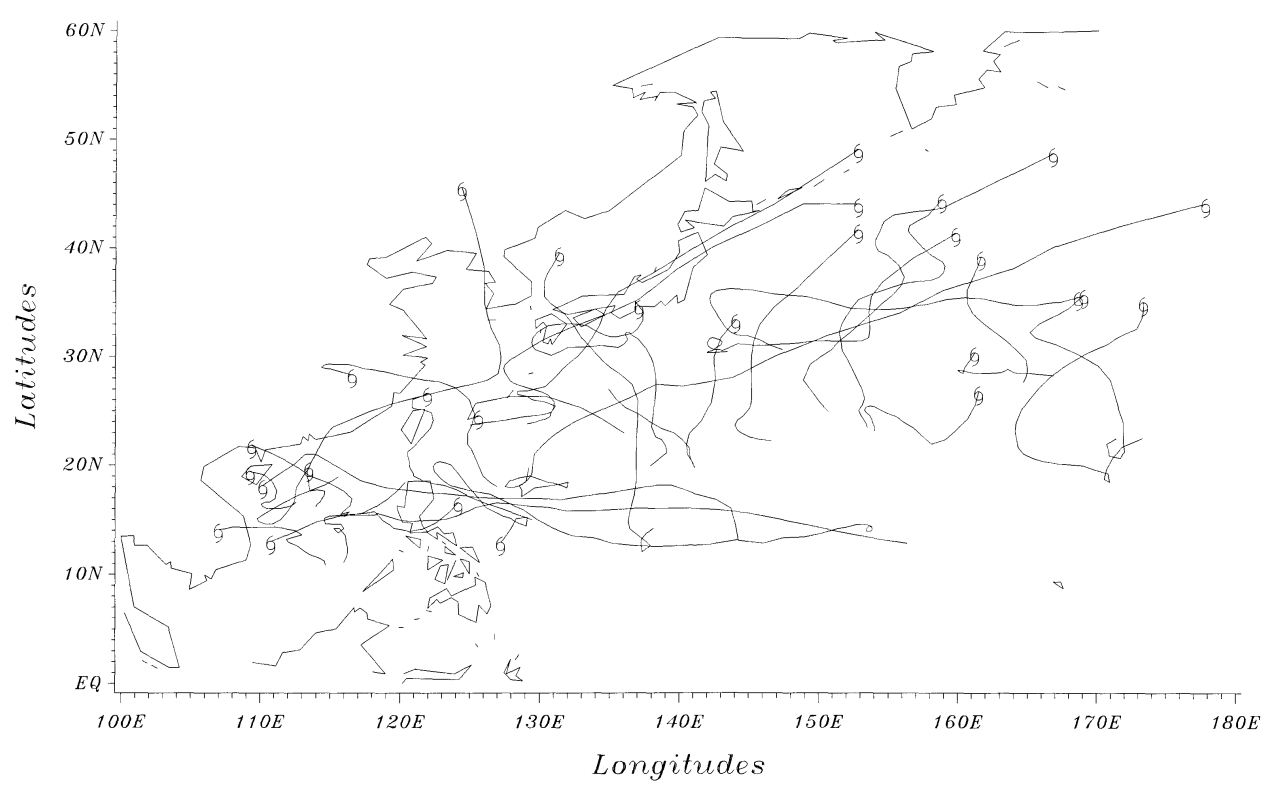

Fig. 2.2. The spatial distribution of anomalous tropical cyclone tracks in 5 strongest El Niño (top) and 5 strongest La Niña (bottom) events over the Western North Pacific Ocean Basin, 1958-98.

\subsection{Wind field analyses}

Another key component of the forces determining the recurving-left and recurving-right tropical cyclones is the internal force of tropical cyclones. The relative location of STHP and tropical cyclones controls which direction the tropical cyclones will recurve to. This is because the abrupt change of tropical cyclone tracks is determined by how the internal force of tropical cyclones has been influenced by the re-modification of these large-scale environmental flows and of the weather systems. Niu (1992) shows the internal force 


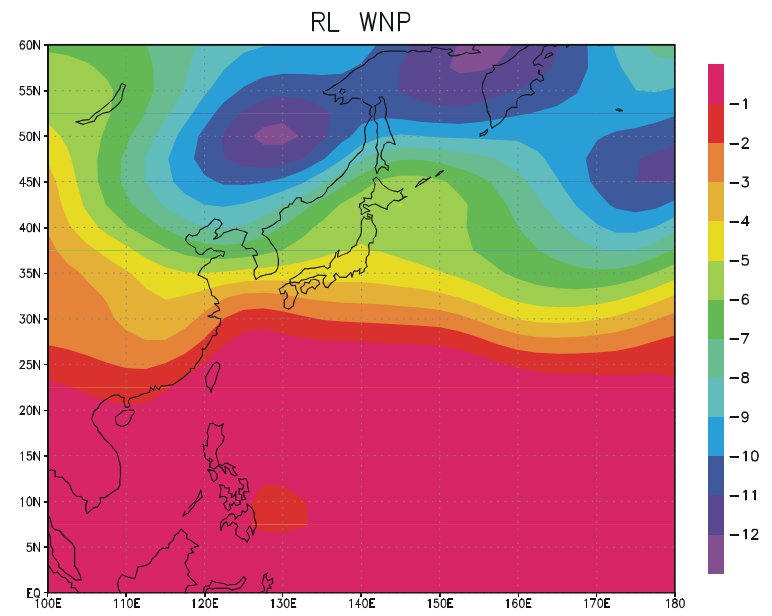

Unit: Decametres

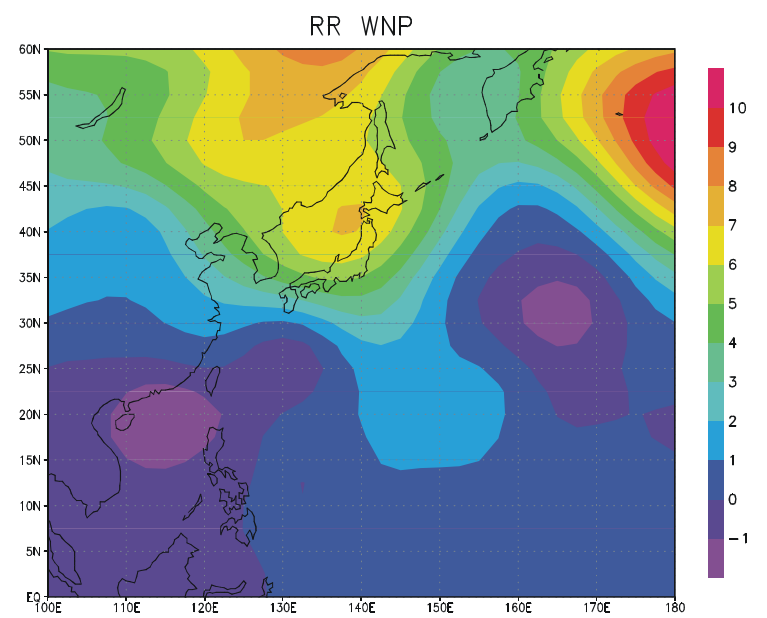

Unit: Decametres

Fig. 3.1. The anomaly of the subtropical tropical high pressure for recurving-left $(\mathrm{RL})$ and recurving-right $(\mathrm{RR})$ tropical cyclones over the Western North Pacific Ocean Basin. Unit: decametres.

$\left(N_{x}, N_{y}\right)$ of a tropical cyclone as follow:

$$
\left\{\begin{array}{l}
N_{x}=-\frac{\overline{d u^{\prime}}}{d t} \\
N_{y}=-\frac{\overline{d v^{\prime}}}{d t}
\end{array}\right.
$$

When the average relative westerly wind increase $\left(\bar{u}^{\prime}>0\right)$, or when the southern part $\left(u^{\prime}>0\right)$ of a tropical cyclone is becoming larger than the northern part of it $\left(u^{\prime}<0\right)$, e.g. the approach of an equatorial high pressure towards a tropical cyclone from its south, then

$$
\frac{\overline{d u^{\prime}}}{d t}>0, \quad N_{x}<0
$$

the internal force of a tropical cyclone would be westward. On the contrary, if the average relative easterly is increasing $(\bar{u}<0)$, or when the northern part is developing and becoming stronger than the southern part of it, e.g. a tropical cyclone
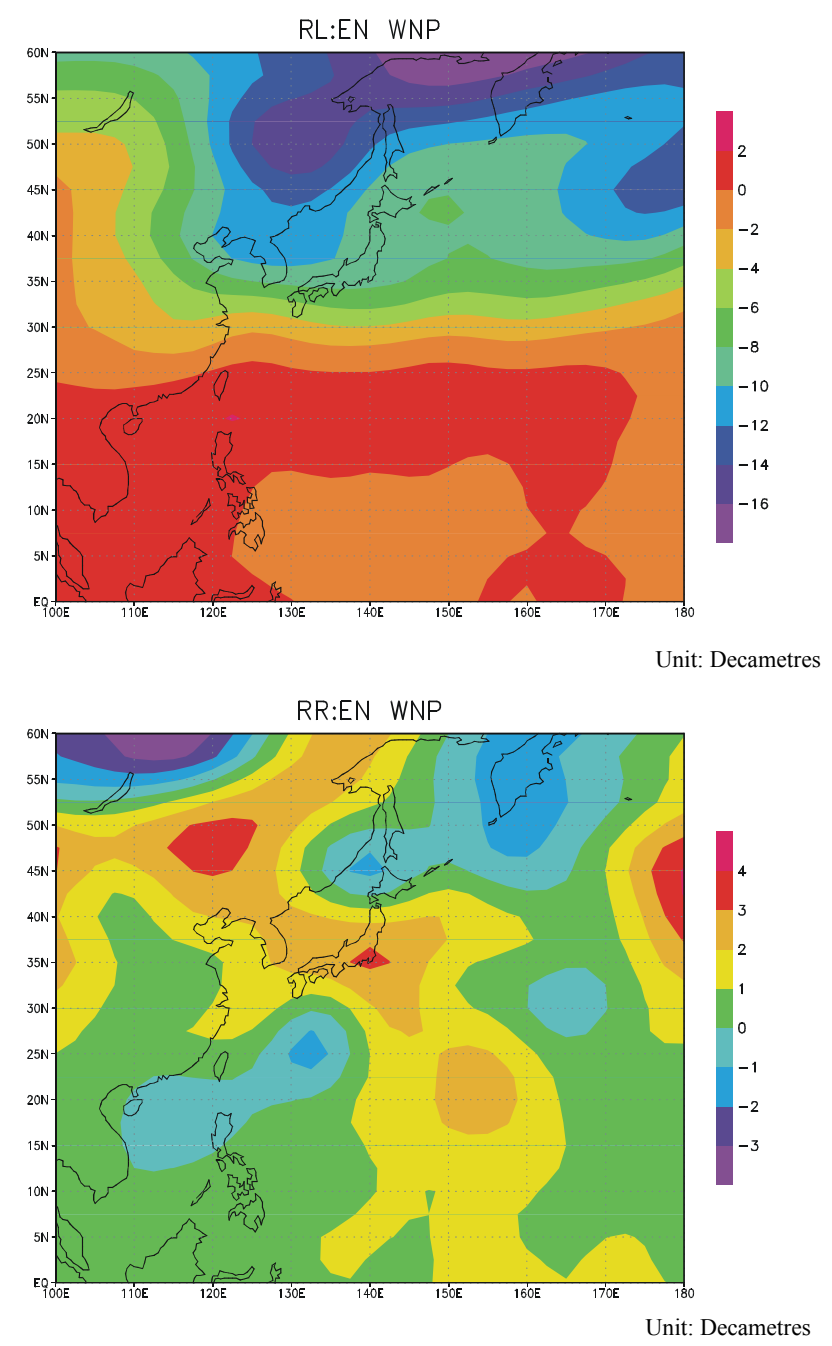

Fig. 3.2. As in Fig. 3.1, but for El Niño (EN) events.

advancing to the vicinity of the sub-tropical high pressure at its north, then

$$
\frac{\overline{d u^{\prime}}}{d t}<0, \quad N_{x}>0
$$

and the tropical cyclone inclines to have an eastward internal force. It is opposite when the tropical cyclone is weakening. If a tropical cyclone does not develop, or

$$
\frac{\overline{d u^{\prime}}}{d t}=0, \quad N_{x}=0
$$

there would be no internal force.

At the same time, when the average relative southerly flow is increasing $\left(\overline{v^{\prime}}>0\right)$, or when the eastern part $\left(v^{\prime}>0\right)$ of a tropical cyclone is becoming larger than the western part of it $\left(v^{\prime}<0\right)$, e.g. the sub-tropical high pressure moving equatorwards at the east of a tropical cyclone, then

$$
\overline{\frac{d v^{\prime}}{d t}}>0, \quad N_{y}<0
$$



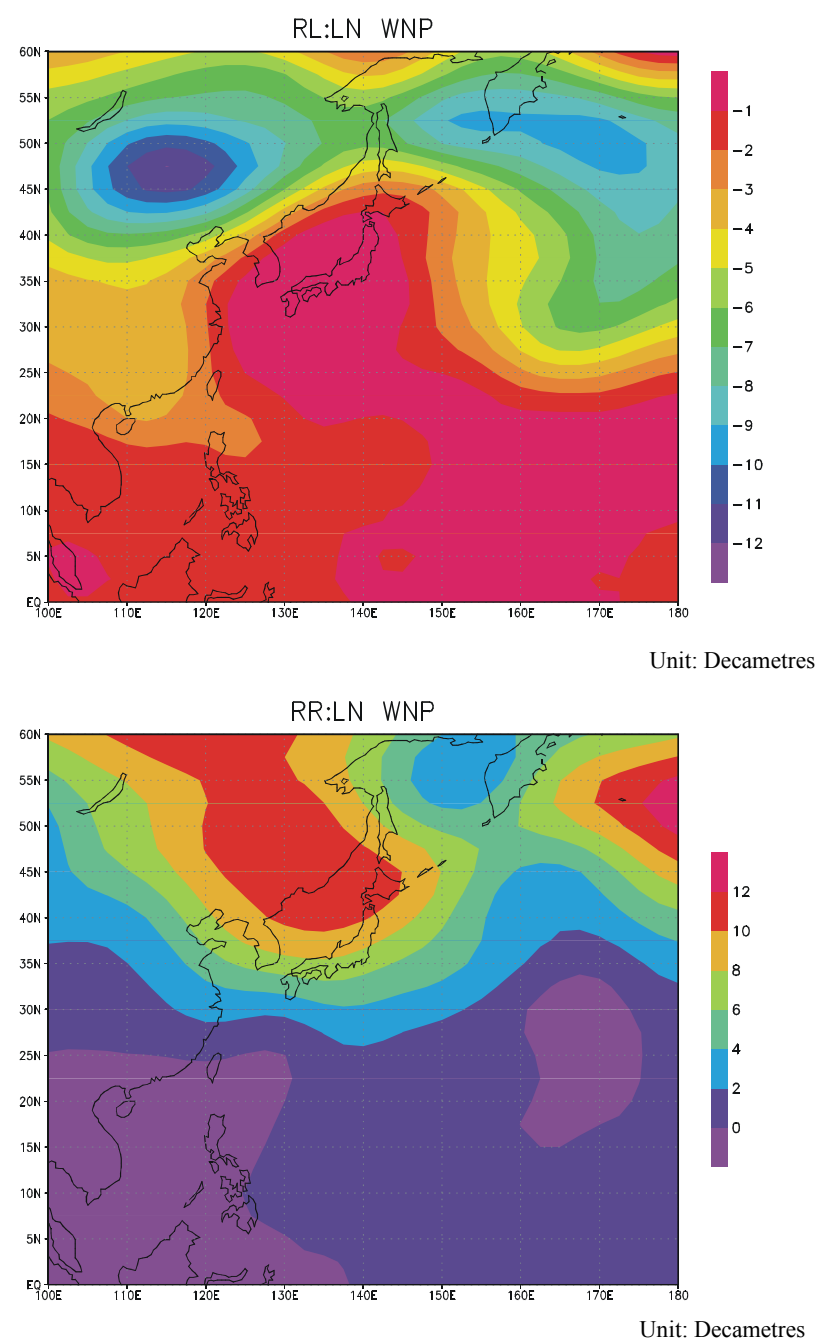

Fig. 3.3. As in Fig. 3.1, but for La Niña (LN) events.

the tropical cyclone would tend to have a southward internal force. When the average relative northerly wind is strengthening $\left(v^{\prime}<0\right)$, or when the western part of a tropical cyclone is developing and becoming larger than the eastern part of it, e.g. a tropical cyclone getting closer to a continental high to its west, then

$$
\frac{\overline{d v^{\prime}}}{d t}<0, \quad N_{y}>0
$$

and the tropical cyclone would have an internal force towards the north. It would be the opposite when a tropical cyclone is weakening. If a tropical cyclone is not developing or

$\frac{\overline{d v^{\prime}}}{d t}=0, \quad N_{y}=0$

it has no internal force. Owing to their own characteristics of each RL and RR tropical cyclone, an investigation of the cases of RL and RR cyclone tracks over the Western North Pacific Basin screened out after the fuzzy method is undertaken (Fig. 3.4).

\section{El Niño}

It is found that during El Niño events, the abrupt change of the westerly trough may be able to enhance the intensity of STHP and/or push it southward so as to strengthen the development of the northern part of tropical cyclones (e.g. RL9129) to recurve left or directly act as a dominant steering current to forcibly recurve the direction of tropical cyclones by augmenting the development of the eastern part of the vortex (e.g. RL9420). However, there is a tendency under strong cross-equatorial flow the tropical cyclones to be recurved northward or northwestward. With a supply of strong southerly wind from three cross-equatorial airflows located roughly at $105^{\circ}-110^{\circ} \mathrm{E}, 125^{\circ}-135^{\circ} \mathrm{E}$ and $145^{\circ}-155^{\circ} \mathrm{E}$, RR9712 and RR9713 were adjusted to move northward.

\section{$\underline{\text { La Niña }}$}

It is seen that under La Niña events, the retreat of the STHP eastward and/or the decreasing intensity of it tend to make tropical cyclones (e.g. RL7429) lose the steering current, resulting in recurving movements. Certainly, when the STHP is stretching southward under the re-adjustment of the westerly trough, the easterlies of the STHP would recurve the tropical cyclones as well. The recurving of RR9804 was clearly caused because of the stretching of sub-tropical high pressure southwards from $25^{\circ} \mathrm{N}$ to $15^{\circ} \mathrm{N}$ to the east of it. Without any other weather disturbances, typhoon 9804 was steered northwestward along the STHP.

\section{Conclusions}

The evidence of this study supports the claim that the occurrences of recurving-left and recurving-right tropical cyclones are related to the modification of steering currents, in which the tropical cyclones are embedded, including the re-adjustment of the westerly trough, the expansion or contraction of the sub-tropical high pressure, the intensifying easterly flow and the strengthening of the cross-equatorial flow. These changes can occur in El Niño and La Niña events. Evidently, there is a higher chance of occurrence of anomalous tropical cyclone trajectories in El Niño rather than La Niña events, but there is not any pronounced spatial pattern of anomalous tropical cyclone tracks. By applying fuzzy method to analyze the pressure-field, it is seen RL (RR) tropical cyclones tend to occur when the subtropical high pressure is weak (strong) in El Niño and La Niña events. More importantly, how the internal force of the tropical cyclones changes by the steering current is determined by the relative location of tropical cyclones to the re-adjustment of these weather systems. These combined analyses can show when and where recurving-left and recurving-right tropical cyclones occur in El Niño and La Niña events. 


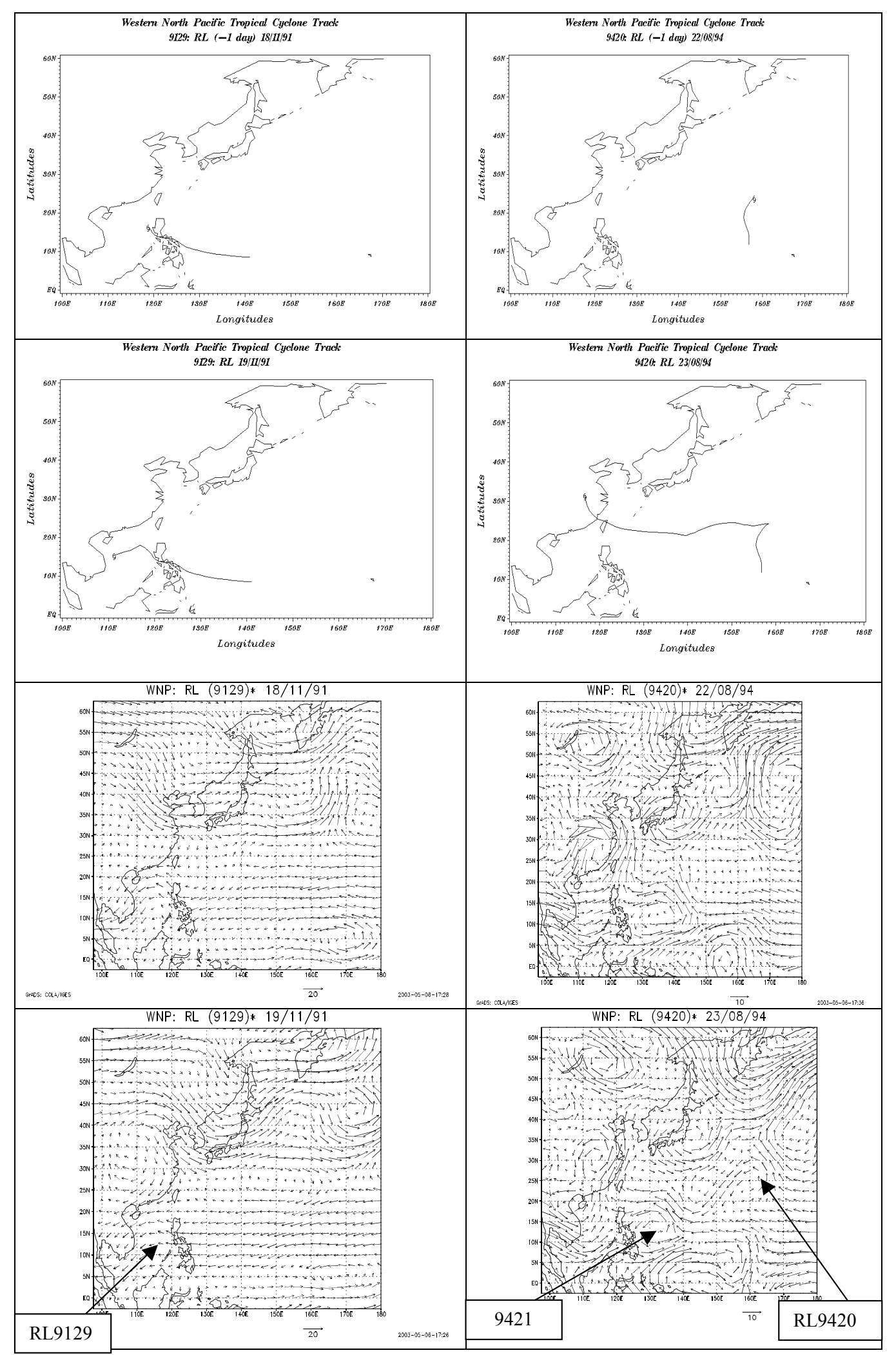

Fig. 3.4. Examples of recurving-left and recurving-right tropical cyclones over the Western North Pacific Ocean in El Niño (RL9129, RL9420, RR9712, RR9713), and La Niña (RL7429, RR9804). Shown are the paths up to 24 hours before the directional change (the top), plus the rest of it after the change (the upper middle), and the wind circulation ( $\mathrm{m} / \mathrm{s}$ ) at $850 \mathrm{hPa}$ at $-24 \mathrm{~h}$ (the lower middle) and $0 \mathrm{~h}$ (the bottom) in which the abrupt recurving occurred. RL is recurving-left cyclones, RR is recurving-right cyclones, the first two digits are the year and the last two digits are the number of tropical cyclones formed in that year. 


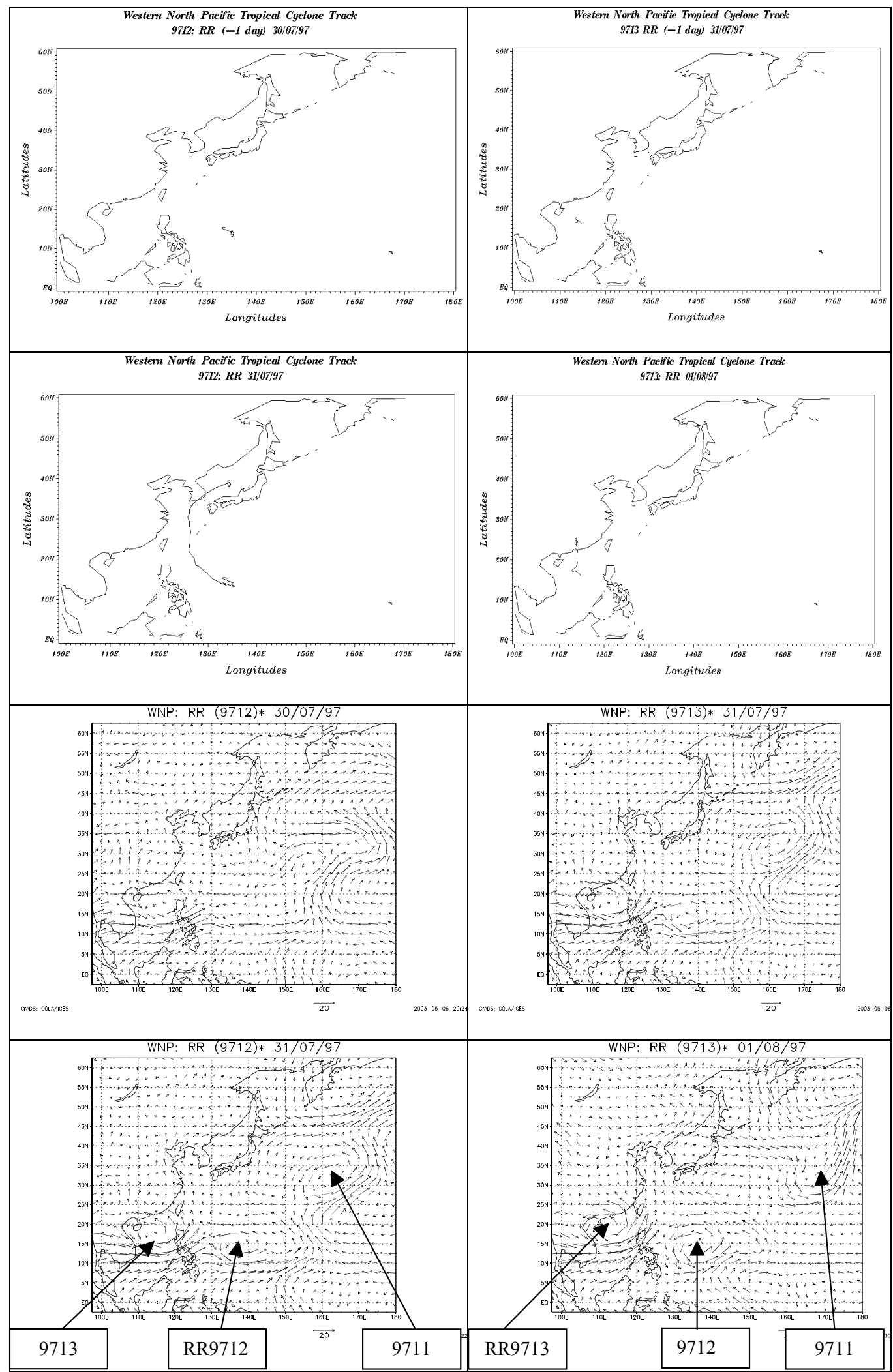

Fig. 3.4. Continued. 


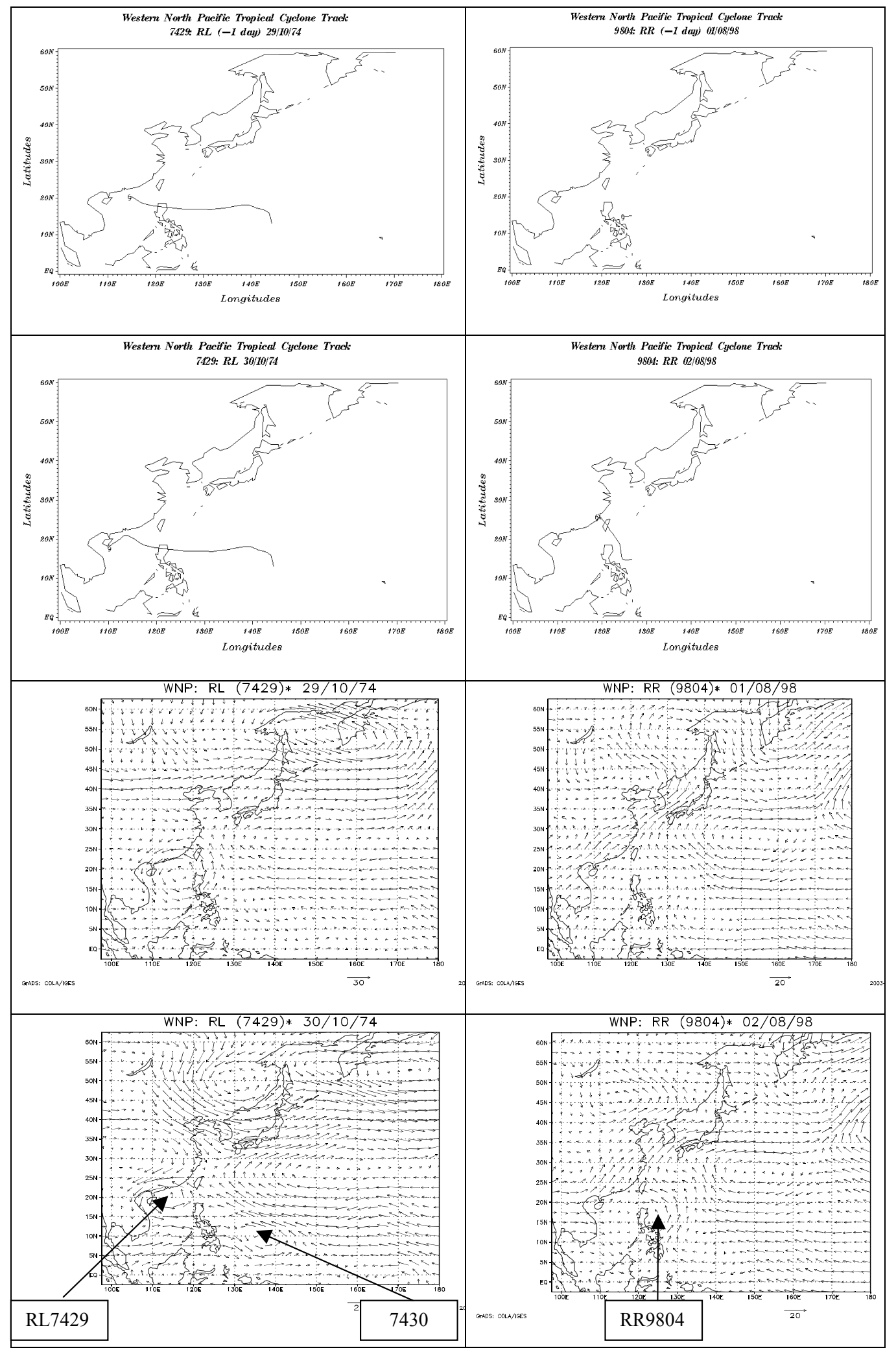

Fig. 3.4. Continued. 


\section{Appendix A STHPI}

Two indices of the sub-tropical high pressure (STHPI) of Central Meteorological Observatory, China, are adopted (see Ding, 1994): The area index is defined as the total number of grid points that have geopotential height of 588 decameters or greater in the region of $110-180^{\circ} \mathrm{E}$, poleward of $10^{\circ} \mathrm{N}$. The intensity index is defined as the accumulative sum of the geopotential height equal to or greater than 588 decameter in the region of $110-180^{\circ} \mathrm{E}$, poleward of $10^{\circ} \mathrm{N}$, with 588 (decameter) $=1,589=2,590=3$, etc.

Acknowledgements. The author thanks Dr. Richard Washington for continuing support and discussion in his DPhil thesis, School of Geography and the Environment, University of Oxford, United Kingdom.

Edited by: P. Fabian and J. L. Santos

Reviewed by: H. Dijkstra and J. L. Santos

\section{References}

Chan, J. C. L. and Gray, W. M.: Tropical cyclone movement and surrounding flow relationships, Mon. Wea. Rev., 110, 13541374, 1982.

Cheung, N. K. W.: Tropical cyclone formation and movement in the Western North Pacific and North Indian Ocean Basins: the roles of ENSO and the Asian monsoon, DPhil thesis, School of Geography and the Environment, University of Oxford, UK, 2004.

Ding, Y. H.: Monsoons over China, Kluwer Academic Publishers, Dordrecht, 1994.

Niu, X. X.: Tropical Cyclone Dynamics, China Meteorology Press, Beijing, 306pp., in Chinese, 1992.

South China Typhoon Research Committee: A Preliminary Study of Complex Typhoon Tracks in South China Sea in Autumn, China, in Chinese, 1977.

South China Typhoon Research Committee: A Preliminary Study of Complex Typhoon Tracks in South China Sea in Early and Mid-Summer, China, in Chinese, 1978.

Yu, S. H. and Lu, S. Y.: Introduction to tropical climatology, China Meteorological Press, Beijing, in Chinese, 1986. 